\title{
LA FUNDACIÓN DE LA ACADEMIA FRANCESA
}

\author{
Marcos Víquez Ruiz
}

\begin{abstract}
RESUMEN
Este artículo presenta la información más importante de la fundación de la Academia Francesa (1635). Comienza con el legado de "Akademos", en cuyos jardines Platón hablaba sobre filosofía. Continúa con la contribución del Renacimiento Italiano, particularmente del "Hotel de Rambouillet", el aposento literario privado de la Marquesa de Rambouillet. Finalmente, se enfatiza la participación de los precursores de la fundación de la Academia: el Cardinal de Richelieu, el estudiante Valentin Conrart, en cuya casa se reunió un círculo de escritores y hombres de letras, progenitores de la idea de la Academia, Boisrobert, Cerisay, Desmarets, Faret, Godeau, Gombauld, Malleville, el abad de Serisy y Vaugelas.
\end{abstract}

\begin{abstract}
This article presents the most relevant information on the establishment of the French Academy (1635). It begins with the legacy of Akadmus, in whose gardens Plato exposed his philosophy, as well as with the contribution of Renaissaance Italy and particularly of "Hotel de Rambouillet", the private literary room of Marquise de Rambouillet, Finally, the article highlights the participation of the direct forerunners of the establishment of the Academy: Cardinal de Richelieu, the scholar Valentin Conrart, whose house served as a gathering place for a circle of writers and men of letters from whose minds arose the idea of this establishment, Boisrobert, Cerisay, Desmarets, Faret, Giry, Godeau, Gombauld, Malleville, the abbot of Serisy and Vaugelas.
\end{abstract}

\section{Génesis del término "Academia"}

El término "Academia" procede de "Akademos", héroe griego y destacado atleta, quien donó a los atenienses veinte estadios de terreno con el propósito de destinarlos a la enseñanza pública.

Hiparco, hijo de Pisistrato, los rodeó con una muralla. Cimón los mandó desecar por medio de un acueducto, e hizo plantar cedros, cipreses y olivos, formando exquisitas alamedas. Dentro de este original espacio, el Amor y las Gracias tuvieron hermosísimas estatuas; se edificaron altares en honor a Hércules y Prometeo, así como un santuario a Minerva.

De ahí que, los antecedentes más remotos del vocablo "Academia" son los referentes a la "Academia" fundada por Platón. 
Platón explicó filosofía en los jardines de Akademos. A la filosofía platónica se le dio el nombre de académica y academismo al entusiasmo de sus numerosos discípulos. Las modificaciones experimentadas por las doctrinas de Platón dieron origen a la aparición de posteriores academias. Así conocemos: la Antigua, o de las doctrinas puras de Platón; la Segunda, fundada por Argesilao; la Nueva, instituida por Carnéades; la Cuarta, abierta por Filo, y la Quinta, dirigida por Antíoco (Saínz de Robles 1972: 15-16).

Por las razones anteriores, Platón y la reunión de discípulos en el jardín de Akademos son los precursores lejanos de la Academia Francesa; sin embargo, es de Italia de donde proviene esta influencia.

El nombre de academismo y de academia se mantuvo. En la Italia renacentista se dio, indiferentemente, a las distintas asociaciones de literatos, eruditos, artistas y a las instituciones docentes de diversa estirpe. En el siglo diecisiete, en Italia, hubo aproximadamente una cincuentena de Academias.

En Francia, la apertura de salones dedicados al cultivo de las bellas letras y de las relaciones sociales, siembran la semilla que posteriormente hará germinar, en las reuniones en casa de Valentin Conrart, la futura "Académie Française".

A l'image de l'Italie, la mode des académies se répand dans toute l'Europe humaniste, mais plus particulèrement en France. Cette diffusion est favorisée par la longue tradition des cercles lettrés et humanistes (...) et par les habitudes d'une société où les salons forment déjà les centres de la vie littéraire (Demougin 1987: 8).

\section{Los salones literarios}

\subsection{El salón de la marquesa de Rambouillet (1588-1665)}

Hija del embajador de Francia en Roma, Jean de Vivonne, marqués de Pisani, y de Julie Savella, gran dama romana, Catherine de Vivonne, convertida por su matrimonio en marquesa de Rambouillet, fue la primera en reunir, en su "Hôtel de Rambouillet"(casa señorial), todos los martes, durante varias décadas, a las damas y a los señores de la nobleza, llamados en aquella época "les précieuses" ("las preciosas") o "les précieux"("los preciosos"), porque hicieron gala de la elegancia exagerada hasta la afectación:

Un dernier caractère de la langue des précieux est à remarquer: ils parlent comme les livres, en belles phrases littéraires (Lanson 1970: 405).

Hacia 1620 se puso en boga el salón literario, típica expresión de la sociedad refinada, inciado, entonces, por la marquesa de Rambouillet.

En estas selectas reuniones de la calle Saint-Thomas-du-Louvre, en las que se hablaba de literatura, poesía y arte en general, los invitados se hacían acompañar también por escritores y eruditos que ellos apadrinaban, entre los que asistían Malherbe, Ménage y Racan.

A l'Hôtel de Rambouillet, on chante, on fait de la musique, on s'amuse à de petits jeux; mais le grand plaisir est celui de la conversation. Un art délicat se forme, qui n'a point de règles, hors celles de la bienséance: il faut savoir parler de tout, et plaire en piquant l'intérêt. Les questions littéraires surtout sont à l'honneur (Castex 1954: 194). 
La marquesa de Rambouillet tuvo, pues, el primer salón que se vio en Francia, y entre los diversos aposentos que componían el hotel, se hizo especialmente famosa la "Chambre bleue", la habitación usual de la marquesa, cuya decoración era totalmente nueva. Arthénice (anagrama de Catherine) fue, también, la primera en tener la idea de pintar una sala de otro color que rojo o de cuero curtido. En esta "academia" privada, alrededor del lecho de la marquesa, además de sus familiares más cercanos, se hallaban agrupados los invitados.

A fines del reinado de Henri IV se produce un hecho considerable: la clase aristocrática se organiza como sociedad mundana. Durante dos siglos, la literatura estará destinada exclusivamente a ese círculo selecto y cerrado. Los agentes de esa transformación, que fue lenta, fueron los literatos (principalmente d'Urfé, que desempeñó el papel de un manual de buenas maneras) y las mujeres (principalmente la marquesa de Rambouillet) (Lanson 1956: 139-140).

En esta sociedad aristocrática tuvo éxito la novela en prosa y verso Astrée, de Honoré d'Urfé (1568-1625), en la que imitaba a los griegos, latinos, italianos y españoles, considerada durante casi veinte años como una especie de manual de la buena compañía.

Vincent Voiture (1598-1648), conversador agradable y perspicaz, autor de cartas y poesías famosas en su tiempo, fue el líder de tal sociedad, a la que también perteneció JeanLouis Guez de Balzac (1597-1654), hábil escritor que aplicó a la prosa el mismo procedimiento depurativo que François de Malherbe le hizo a la poesía. Especialmente, es conocida su Correspondance, modelo de bella prosa.

Posteriormente, se presentarán en casa de la marquesa de Rambouillet, madame de La Fayette (1634-1693), autora de La princesse de Clèves (1678) y madame de Sévigné (16261696), quien cultivó el género epistolar.

Asimismo, una de las contertulias más importantes del famoso "Hôtel de Rambouillet" fue mademoiselle de Scudéry, quien abrió su propio salón, en la calle de Beauce.

\subsection{El salón de Madeleine de Scudéry (1607-1701)}

Una vez que el "Hôtel de Rambouillet" dejó de representar un papel en la vida literaria y mundana de París; a partir de 1652 y hasta 1657 los burgueses y profesionales de letras se reunían los sábados, donde mademoiselle de Scudéry, una mujer culta, educada y fértil narradora que impulsó la novela de aventuras.

En sus largas novelas "heroicas": Artamène ou le grand Cyrus (1649-1653) y Clélie (1654-1669), que comprenden cada uno diez volúmenes, mademoiselle de Scudéry pintó la sociedad preciosista a la que perteneció.

S'il fallait un mot pour définir les modes de penser et d'écrire du salon de Mlle de Scudéry et des très nombreux cercles qui se formèrent alors à Paris, celui de préciosité s'imposerait. (...) On se servit alors du terme de précieuses pour désigner certaines femmes jugées ridicules, et qui raffinaient à l'excès sur le sentiment et sur le langage (Adam 1967: 174).

En la época, otros salones literarios fueron sostenidos y dirigidos por mujeres burguesas como madame Scarron, madame des Loges, madame d'Auchy y madame de La Sablière, en donde se reunían Molière, La Fontaine y Boileau, entre otros. En el salón de madame De Sablé, La Rochefoucauld ensayó sus Maximes. 
El ejemplo de la marquesa de Rambouillet se imitó profusamente: en todo el París dintinguido de la época, alrededor del Louvre y del Palais-Cardinal, en el Marais y en la Place Royale, los palacios de los príncipes y de los grandes señores e incluso los caserones de la burguesía rica abrieron sus puertas. Callejones literarios, callejones mundanos, callejones a la vez mundanos y pedantes se multiplican durante la primera mitad del siglo, y el contagio se extiende hasta las provincias (Lanson 1956: 149).

Los hombres cultos no se quedaron al margen de estas reuniones, y siguiendo el ejemplo de la marquesa de Rambouillet, celebraron sus propias sesiones, pero sin la participación femenina.

\section{La Academia Francesa}

En 1626 un círculo de escritores y aficionados a la literatura, entre los que figuran Cerisay, Chapelain, Giry, Godeau, Gombauld, los dos Habert, Malleville, el abad de Serisy y Vaugelas, adquirieron la costumbre de reunirse en casa del erudito Valentin Conrart' para conversar sobre temas literarios y leer sus propias obras. Con excepción de Gombauld, quien tenía cincuenta años de edad, los ocho restantes eran más jóvenes; además, casi todos disfrutaban de una situación socio-económica estable.

Estas reuniones derivaron en una pequeña sociedad que creció muy pronto, al aceptar en su seno a Faret, Desmarets y a Boisrobert, quien informó al Cardenal de Richelieu² acerca de estas doctas tertulias.

El Cardenal tenía muchísimo interés en las "bellas letras", y soñaba, a la vez, con colocar a los escritores bajo su cúpula, ocasión que aprovechó para ofrecerles, en 1629, su protección real:

Richelieu, informé par Boisrobert de ces rendez-vous, invita ces messieurs à constituer un corps et leur promit la protection royale (Sage 1962: 149).

$\mathrm{Al}$ inicio, esta pequeña sociedad se componía de veintisiete miembros. La primera sesión oficial se celebró el 13 de marzo de 1634 y el 20 de marzo del mismo año, la Asamblea resolvió llamarse "Académie Française"4. El 29 de enero de 1635, la institución fue fundada mediante las Cartas patentes ${ }^{5}$ del rey Louis XIII, que el Parlamento registró tres años más tarde, luego de algunas oposiciones.

Le Parlement, inquiet et jaloux de la constitution d'un nouveau corps, dont il ne concevait pas nettement les attributions, refusa pendant longtemps d'enregistrer les lettres patentes qui établissaient l'Académie; il ne céda qu'au bout de trois ans, le 10 juillet 1637 (Lanson 1970: 406).

Los Académicos, llamados "les immortels", recibieron el cometido de redactar un Diccionario y una Gramática, con el fin de fijar el "correcto" uso de la lengua, de ofrecer a los escritores una Retórica y una Poética y, finalmente, juzgar las obras que les serían entregadas.

Claude Favre de Vaugelas (1585-1650) fue el encargado de la elaboración del Dictionnaire; sin embargo, debido a su deceso no pudo concluirlo, pues tan sólo llegó a la letra "I". Por el contrario, su obra Remarques sur la langue française fue concluida en 1647. 
Vaugelas donna ses Remarques sur la langue française, qui étaient comme le registre de ses observations. C'est un recueil de décisions particulières, précédées d'une préface où l'auteur explique ses principes et sa méthode (Lanson 1970: 408).

Tratando de ortografía, lexicografía, sintaxis y estilo, Vaugelas opinaba que la lengua se encuentra sometida al uso, que puede ser bueno o malo, e indicaba como bueno el de la sociedad cortesana.

Mais il y a un bon et un mauvais usage: qu'est-ce que le bon usage? 'C'est la façon de parler de la plus saine partie de la cour, conformément à la façon d'écrire de la plus saine partie des auteurs du temps (Lanson 1970: 408).

\section{$\mathrm{Al}$ respecto, Castex y Surer opinan como Lanson:}

Il (Vaugelas) définit sa méthode dans une importante préface: ainsi que Malherbe, il reconnaît l'usage comme le seul criterium valable en matière de langage; mais il rejette l'usage du peuple et n'admet que le "le bon usage", c'est-à-dire "la façon de parler de la plus saine partie de la Cour" (1954: 191).

La mayor parte de los primeros estatutos de la Academia fueron redactados por el Académico Jean Chapelain (1595-1674).

En las reuniones de los lunes, cada Académico debía pronunciar un discurso, que por lo general no trataban temas estrictamente literarios. Chapelain habló Contre l'amour y Gombauld sobre el Je ne sais pas quoi, Racan Contre les sciences y Porchères d'Arbaud sobre l' Amour et l'Amitié. Des Marests expuso sobre l'Amour spirituel y Boissat sobre la defensa del Amour des corps. Otros trataron el tema de l'Eloquence, del Théâtre, la Poésie, le Style philosophique y la Traduction.

Cada participación no podía exceder los tres cuartos de hora, por lo que media hora era el tiempo normal. Al respecto, Antoine Adam reproduce parte de una carta que Faret escribió a Antoine Brun, en marzo de 1635:

On s'assemble toutes les semaines, et à toutes les entrées, chacun fait une harangue de demy-heure sur tel sujet que l'on veut choisir. De ces harangues, on fera un volume du bout de l'an, qui sera la plus belle chose qui se soit vue depuis les Anciens (Adam 1962: 229).

Durante cuarenta años, la Academia Francesa no tuvo un lugar definido para celebrar sus sesiones, hasta que en 1672, Louis XIV le dio asilo en el Louvre. Por lo demás, en 1806 Napoléon le concedió un lugar definitivo en el palacio de "l'Institut", fundado por Mazarin, en donde se encuentra hoy día.

A la mort de Séguier, au début de 1672, c'est Louis XIV lui-même qui lui succède comme protecteur de la Compagnie. Il la loge au Louvre dans un appartement qui est meublé magnifiquement à cet effet; une bibliothèque est mise à sa disposition (Clarac 1969: 15).

Desde sus primeras decisiones, la Academia postula la soberanía del francés sobre los demás idiomas. Faret dice:

Notre langue, plus parfaite déjà que pas une des autres vivantes, pourroit bien enfin succéder à la latine, comme la latine à la grecque, si l'on prenoit plus de soin... de l'élocution (Von Wartburg 1966: 191). 
Los cuarenta primeros académicos fueron no solamente escritores, sino también eruditos, abogados, médicos y hombres de Estado: Godeau, Gombauld, Chapelain, los dos Habert, Conrart, Serisay, Malleville, Faret, Desmarets, Boisrobert, Bautru, los dos Du Chastelet, Silhon, Sirmond, Bourzeys, Meziriac, Maynard, Colletet, Comberville, SaintAmand, Colomby, Baudouin, l'Estoile, de Porchères, Baro, Racan, Servien, Balzac, Bardin, Boissat, Vaugelas, Voiture, Laugier, Montmor, La Chambre, Seguier, Giry, Granier.

Los grandes escritores del siglo diecisiete elegidos como Académicos fueron, en orden cronológico: Pierre Corneille (1647), Jacques-Besigne Bossuet (1671), Jean Racine (1673), Jean de La Fontaine (1684), La Bruyère (1693).

Debido a los prejuicios de la época, a los actores no se les permitía e! ingreso como Académicos; tal es el caso del más grande de los autores teatrales franceses y gran maestro de la comedia y de la farsa, Jean-Baptiste Poquelin, conocido como Molière (1622-1673).

Molière n'en fut pas, parce qu'il était acteur et par conséquent n'avait pas, selon les préjugés, les "bonnes moeurs" exigées pour être reçu (Denoeu 1967: 79).

Los primeros académicos fueron discípulos de François de Malherbe (1555-1628). Todos entendían la crítica literaria como la concebía el adversario de la "Pléyade". En este mismo sentido, a solicitud expresa del Cardenal, en 1637 redactaron las Observations de l'Académie sur le Cid. A criterio de Sage, la intervención de la Academia contra el Cid "manque de justesse et d'habileté" (1962: 150).

El Dictionnaire de l'Académie française conoció la primera edición en 1694, la segunda en 1718, la cuarta en 1762, la sétima en 1879 y la octava fue publicada, casi dos siglos y medio después, en 1932. En este último año, se editó finalmente la Grammaire de l'Académie française.

Como ha sido ya señalado, Le Dictionnaire contenía solamente el habla de la sociedad culta. A excepción de los términos de caza, de heráldica y de guerra, que caracterizan el carácter aristocrático de la época, las restantes palabras técnicas están ausentes.

Para Molière y La Fontaine, el empobrecimiento de la lengua es innegable.

Le Dictionnaire académique vaut pour Racine: il est trop pauvre pour Molière et pour La Fontaine, qui ont besoin de signes moins éloignés et moins dépouillés des sensations naturelles (Lanson 1970: 410).

La Rhétorique nunca salió a la luz, y la Poétique que había proyectado, fue La Ménardière, médico doméstico de madame de Sablé, quien la publicó.

La mission que Richelieu avait assignée à l'Académie ne fut remplie dans aucune de ses parties. Le dictionnaire ne parut que dans le dernier quart du siècle, et la grammaire resta, pour trois cents ans, à l'état de projet. Le scandale que firent les Observations sur "le Cid" décida les académiciens à ne plus s'occuper des oeuvres contemporaines (Adam 1967: 173).

En conclusión, la herencia platónica en los jardines de Akademos, unida al legado de las Academias que florecieron en la Italia renacentista, así como la apertura de los salones literarios privados en París, principalmente el "Hôtel de Rambouillet" de Catherine de Vivonne, marquesa de Rambouillet; son los precursores -unos más lejanos y otros más cercanos- de las reuniones literarias en casa del erudito Valentin Conrart, de donde germinó la fundación de la "Académie Française". 
Desde 1639, esta Institución cuenta con cuarenta Académicos y generalmente no elige miembros correspondientes ni asociados. Sin embargo, con la elección de Julien Green (1971), luego de Marguerite Yourcenar (1980) y de Léopold S. Senghor (1983), se abrió sucesivamente a los extranjeros francófonos y a las mujeres.

Actualmente, entre otras funciones, la "Académie Française" se encarga del otorgamiento de premios literarios.

\section{Notas}

1. Valentin Conrart nació en París en 1603 y provenía de una familia adinerada de Valenciennes. Vivía en la calle Vieilles-Etuves, cerca de la calle Saint-Martin y ocupaba el cargo de secretario consejero del rey. Ignoraba el latín y el griego, pero conocía muy bien el español, el italiano, y sobre todo, el francés.

2. Armand Jean du Plessis, cardinal de Richelieu (1585-1642). Hombre de Estado, Richelieu es también un hombre de letras. Como obispo escribió Les Principaux Points de la foi de l'Eglise Catholique (1617); Instruction du chrétien (1620); Traité de la perfection du chrétien (1646). En 1642 redactó un Testament, en donde justifica sus concepciones políticas.

3. Actualmente se le conoce también a la "Académie Française" como la "Coupole".

4. Según A. Adam (1962: 220), la idea de fundar una Academia no era nueva, pues anteriormente se habían formado varios grupos, que habrían merecido este nombre. Antes del definitivo de "Académie Française", circularon otros nombres: "Académie des beaux esprits", "Académie éminente", "Académie de l'éloquence" y "Académie des Polis".

5. Las Cartas patentes especificaban que la función principal de la "Académie" era: "donner des règles certaines à notre langue et à la rendre pure, éloquente et capable de traiter les arts et les sciences" (Denoeu 1967: 79).

6. Grupo de poetas que, alrededor de Pierre de Ronsard (1524-1585), se proponía renovar la poesía francesa con el fin de separarla de las normas impuestas por la tradición medieval.

Además de Ronsard y de Du Bellay (1522-1560), el grupo de la "Pléyade" comprendía a Jean Dorat o Daurat (1508-1588), Remy Belleau (1528-1577), Jean-Antoine de Baif (1532-1589), Pontus de Tyard (1521-1605) y Etienne Jodelle (1532-1573).

\section{Bibliografía}

Adam, Antoine. 1962. Histoire de la littérature française au XVIIe. Siècle. Paris: Editions Mondiales.

Adam, Antoine et autres. 1967. Littérature française. Des origines à la fin du XVIIIe Siècle. Paris: Larousse.

Castex, Pierre et Paul Surer. 1954. Manuel des études littéraires françaises: Moyen Âge, XVIe XVIIe Siècles. Paris: Hachette.

Clarac, Pierre. 1969. Littérature française: l'Âge Classique II, 1660-1680. Paris: Arthaud. 
Demougin, Jacques. 1987. Dictionnaire historique, thématique et techinique des Littératures. Paris: Larousse.

Denoeu, François. 1967. Sommets littéraires français. Anthologie-Histoire de la Littérature française des origines à nos jours. Boston: D.C. Heath and Company.

Lanson, G. 1970. Histoire de la Littérature française. Paris: Hachette.

Lanson, G. y P. Tuffrau. 1956. Manual de historia de la literatura francesa. Traducción de Juan Petit. Barcelona: Labor.

Sage, Pierre et Raoul Morçay. 1962. Histoire de la littérature française: le Préclassicisme. Paris: Editions Mondiales.

Sainz de Robles, Federico C. 1972. Ensayo de un diccionario de la literatura. Madrid: Aguilar.

Vier, Jacques. 1959. Histoire de la Littérature française. XVIe - XVII e Siècles. Paris: Armand Colin.

Von Wartburg, Walther. 1966. Evolución y estructura de la lengua francesa. Versión española de Carmen Chust. Madrid: Gredos. 